\title{
Pengaruh lama maturasi pada sintesis komposit hydroxyapatite-polyethylene glycol terhadap kristalinitas dan kekerasan
}

\author{
Atika Rahmawati, Hartatiek*, Nandang Mufti \\ Universitas Negeri Malang, Jl. Semarang No. 5 Malang, Jawa Timur, Indonesia \\ *Penulis korespondensi, Surel: hartatiek.fmipa@um.ac.id
}

Paper received: Paper received: 01-01-2022; revised: 15-01-2022; accepted: 31-01-2022

\begin{abstract}
Abstrak
Hydroxyapatite $\left(\mathrm{Ca}_{10}\left(\mathrm{PO}_{4}\right)_{6}(\mathrm{OH})_{2}\right)$ merupakan salah satu jenis biokeramik yang banyak digunakan dalam aplikasi medis karena sifat-sifatnya yang unggul. Keunggulan dari hidroksiapatit adalah kemiripannya dengan struktur kimia tulang dan jaringan keras pada tulang manusia. Material ini dapat mendorong pertumbuhan tulang baru, serta mempercepat proses penyatuan tulang. Batuan Calcite Puger berpeluang sebagai bahan dasar pembuatan HA, karena calcite Puger mengandung kalsium sebesar 98,36 persen yang berpotensi untuk digunakan pada produksi HA. Untuk memenuhi syarat sebagai material substitusi tulang, HA harus didesain dalam bentuk komposit dengan polimer, karena tulang merupakan komposit alami yang terdiri dari bahan organik dan inorganik. Polyethylene Glycol merupakan salah satu polimer yang dapat digunakan sebagai komposit HA-PEG karena memilki sifat spesifik, yaitu tidak beracun, osteokonduktif, biocompatible, biodegradable, dan hidrofilik. Penelitian ini bertujuan untuk mensintesis HA dengan menggunakan bahan dasar $\mathrm{Ca}(\mathrm{OH})_{2}$ dari calcite Puger, $\mathrm{H}_{3} \mathrm{PO}_{4}$, dan $\mathrm{NH}_{4} \mathrm{OH}$ sebagai pengontrol $\mathrm{pH}$. Metode kopresipitasi digunakan untuk mempreparasi komposit HA-PEG dengan perbandingan 80:20 persen berat. Ukuran kristal, fasa dan kristalinitas dikarakterisasi menggunakan XRD, Fotografi mikrostruktur diamati dengan SEM, perbandingan $\mathrm{Ca} / \mathrm{P}$ dengan menggunakan EDX, dan kekerasan menggunakan vickers hardness. Lama Maturasi komposit HA-PEG adalah 12, 24 dan 36 jam. Dengan metode kopresipitasi, HA yang diperoleh memiliki nilai perbandingan $\mathrm{Ca} / \mathrm{P}$ sebesar 1,68 dan ukuran kristal sebesar 22,87 nm. Hasil yang diperoleh dari karakterisasi XRD menunjukkan bahwa bertambahnya lama maturasi mempengaruhi ukuran kristal dan kekerasan, namun tidak mempengaruhi kristalinitas komposit HA-PEG. Kekerasan komposit HA-PEG hasil sintesis untuk lama maturasi 12, 24 dan 36 jam adalah $43,1,71,2$ dan $64,1 \mathrm{~kg} / \mathrm{mm}^{2}$.
\end{abstract}

Kata kunci: lama maturasi; calcite; komposit HA-PEG; kristalinitas; kekerasan

\section{Pendahuluan}

Hydroxyapatite (HA) dengan rumus kimia $\mathrm{Ca}_{10}\left(\mathrm{PO}_{4}\right)_{6}(\mathrm{OH})_{2}$ merupakan komponen yang membetuk mayoritas komponen tulang dan gigi manuusia, sehingga Hydroxiapatite memiliki perananyang sangat penting dalam regenerasi cacat tulang. Hidroksiapatit dapat disintesis dengan menggunakan batu kapur. Potensi batu kapur di Indonesia cukup besar ketersedianya, terutama dikawasan Puger kabupaten Jember. Batu kapur Puger memiliki kandungan CaO 53,83 - 55,34\%, $\mathrm{MgO} 0,03-0,48 \%, \mathrm{CaCO}_{3}$ 98,74\% dan $\mathrm{MgCO}_{3}$ 1,00\%. Batu kapur dapat digunakan sebagai sumber hydroxiapatite (HA) dimana sangat berguna untuk aplikasi biomedis, bersifat ekonomis dan ramah lingkugan. Material hydroxiapatite (HA) berasal dari sumber alami dapat membentuk ikatan yang kuat dengan jaringan tulang. Hidroksiapatait yang berasal dari batu kapur memiliki kandungan kalsium yang cukup besar (Rachmania, 2012).

Namun hydroxiapatite mempunyai kelemahan yaitu bersifat rapuh, tidak bersifat osteoinduktif, sifat mekanik rendah dan ketidakstabilan struktur pada saat bercampur dengan cairan tubuh. Penyembuhan tulang pada kasus kerusakan tulang merupakan suatu proses yang komplek dimana diperlukan suatu bahan yang mempunyai sifat yang osteoinduksi pada 
hydroxiapatite (HA). Salah satu bahan yang mempunyai sifat tersebut adalah Polyethylene Glycol (PEG). Polyethylene Glycol (PEG) dengan rumus kimia $\mathrm{C}_{2} \mathrm{H}_{6} \mathrm{O}_{2}$ merupakan kelompok polimer sintetik yang larut air dan memiliki kesamaan struktur kimia berupa adanya gugus hidroksil primer pada ujung rantai poliester. PEG memiliki sifat tidak beracun, hidrofilik, fleksibilitas yang tinggi dan biokompatibilitas. (Febrianto, 2011).

Penelitian ini mencoba untuk memperbaiki sifat rapuh hydroxiapatite (HA) dengan cara mengkompositkan dengan PEG, sehingga komposit HA-PEG yang dihasilkan diharapkan memiliki fleksibilitas, biokompatible dan sifat mekanik yang lebih baik sebagai bahan graft tulang.

\section{Kajian Teori}

Hidroksiapatit telah diuji berulang kali sebagai tulang tiruan karena kemiripannya dengan tulang alami meskipun tidak semirip dengan unsur pokok organik seperti kolagen dan polisakarida. HA telah disintesis dan biasanya diproduksi dalam berbagai bentuk implan (padat dan berpori) dan juga sebagai pelapis pada implan lainnya (Park, 2009).

Batuan calcite alam merupakan mineral yang terbentuk melalui proses kristalisasi pada daerah laut dangkal. Batuan calcite termasuk kedalam golongan karbonat dengan komposisi kimia yang sama yaitu karbonat $\left(\mathrm{CaCo}_{3}\right)$, namun terkadang mineral ini juga menyusun batuan yang mempunyai komposisi yang berbeda.

Kristalinitas merupakan faktor penting dalam peresapan HA. Material dengan kristalinitas rendah atau amorf lebih mudah diserap dan lebih cocok jika digunakan pada tulang rawan daripada untuk coating atau pelapis dengan kristalinitas tinggi (Overgaard, 1999).

Coating dengan derajat kristalinitas tinggi memiliki sifat disolusi yang rendah dan lebih stabil dalam jaringan (Le Geros, 1993., Heimann. 2006). Pelapis dengan fase amorfus yang tinggi terurai lebih cepat yang dapat menyebabkan pelemahan yang lebih cepat dan merusak atau menghancurkan pelapis. Bagaimanapun selama ini pelapis amorfus diketahui lebih bermanfaat dalam hal aktivitas fisiologi ( J.Weng, 1997).

Spesifikasi ISO terstandard (ISO 13779-2:2000), untuk membuat HA yang memiliki kekuatan mekanik dalam jaringan yang cukup setidaknya memiliki derajat kristalinitas lebih dari 45\%. Pelapis dengan derajat kritalinitas $66-70 \%$ adalah HAp coating yang paling sering digunakan sebagai bahan biomedis. Park, J. (2009) menunjukkan bahwa kekerasan HAp padat yang diperoleh dari uji vicker hardness adalah antara 3.0 GPa-7.0 GPa.

\section{Metode}

\subsection{Tahap Persiapan}

Semua bahan yang dibutuhkan dalam penelitian dipersiapkan. Ukuran serbuk dari bahan baku penelitian seperti batuan calcite diusahakan homogen, dengan cara diayak dengan ayakan 200 mesh terlebih dahulu. Kalsinasi pada suhu 10000C selama 5 jam dilakukan untuk menghilangkan kadar $\mathrm{CO} 2$ dari serbuk batuan calcite, sehingga diperoleh serbuk $\mathrm{Ca}(\mathrm{OH}) 2$ sebagai sumber kalsium pada sintesis HA. 


\subsection{Tahap Pembuatan}

\subsubsection{Sintesis Hidroksiapatit}

Kalsium diperoleh dari serbuk batuan calcite yang telah dikalsinasi. Fosfat yang digunakan diperoleh dari diammonium hydrogen phosphate acid [(NH4)2HPO4] atau DHP 0,6 M dengan $\mathrm{NH} 4 \mathrm{OH}$ 0,8 M sebagai pengontrol $\mathrm{pH}$. Mula-mula serbuk $\mathrm{Ca}(\mathrm{OH}) 2$ direaksikan dengan HNO3 1M untuk membentuk CaNO3. Langkah selanjutnya CaNO3 direaksikan dengan DHP dan NH4OH distirrer dengan kecepatan 700 rpm selama 1 jam pada temperatur 350C. Penambahan DHP dan $\mathrm{NH} 40 \mathrm{OH}$ dilakukan dengan volume $0,833 /$ menit. Selama proses pencampuran, indikator phenolphtalein (PP) digunakan sebagai pengontrol $\mathrm{pH}$ tetap pada keadaan basa $(\mathrm{pH} \approx 9-10)$. Langkah berikutnya adalah memeram (maturasi) larutan dengan lama 24 jam yang kemudian disaring dan dicuci dengan DI water hingga warna larutan putih bersih tidak lagi berwarna merah muda. Annealing pada temperatur $1000 \mathrm{C}$ selama 24 jam dilakukan pada bahan yang telah disaring dengan tujuan mengeringkan bahan dan mendapatkan kemurnian bahan.

\subsubsection{Sintesis Komposit Hidroksiapatit-PEG}

HA yang kering siap dikompositkan dengan Polyethylene Glycol. HA-PEG dilarutkan dalam aquadest. Kemudian di stirrer selama 3 jam agar kedua bahan terlarut dan homogen. Langkah berikutnya memeram hasil sintesis dengan lama 12, 24 dan 36 jam. Komposit HA-PEG hasil sintesis kemudian dikeringkan pada suhu 100o C selama 24 jam.

\subsection{Tahap Karakterisasi}

Karakterisasi untuk struktur kristal dan kristalinitas menggunakan uji XRD. Sedangkan morfologi dan rasio $\mathrm{Ca} / \mathrm{P}$ ditentukan melalui uji SEM-EDX. Untuk pengujian kekerasan (hardness) dilakukan dengan alat vickes hardness dengan mengukur dalamnya indentasi.

\section{Hasil dan Pembahasan}

\subsection{Data Hasil Uji XRD}

\subsubsection{Pada Hidroksiapatit}

HA hasil sintesis yang diperoleh dicocokkan dengan data highscore plus, terlihat semua puncak-puncaknya cocok. Hal ini berarti fase hidroksiapatit yang diinginkan telah terbentuk.

\section{Gambar 1. Pencocokan Pola XRD}

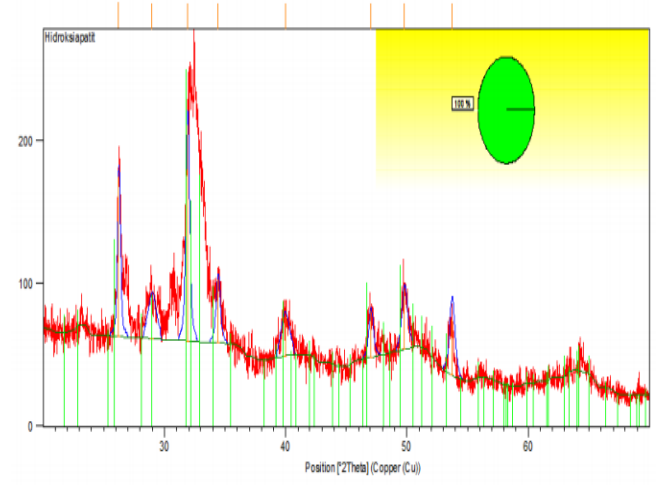


Berdasarkan gambar 1 diatas terlihat bahwa HA berbasis batuan calcite telah berhasil disintesis. Selain menunjukkan keberhasilan sintesis HA pola XRD juga digunakan sebagai penentu ukuran butir dan derajat kristalinitas. Ukuran butir dihitung dengan persamaan scherrer dan menunjukkan bahwa ukuran butir untuk HA adalah $22.87 \mathrm{~nm}$. Sedangkan derajat kristalinitas dihitung melalui persamaan:

$$
\% \text { Kristalinitas }=\frac{\text { Luastotal }- \text { luasamorf }}{\text { luastotal }} \times 100 \%
$$

Dari hasil perhitungan persamaan diatas diperoleh nilai derajat kristalinitas HA sebesar $48.38 \%$.

\subsubsection{Pada Komposit Hidroksiapatit-PEG}

Pola difrkasi hidroksipatit dan komposit hidroksiapatit-PRG ditampilkan pada gambar 2 berikut.

\section{Gambar 2. Hasil XRD Hidroksipatit dan Komposit Hidroksiapatit-PEG}

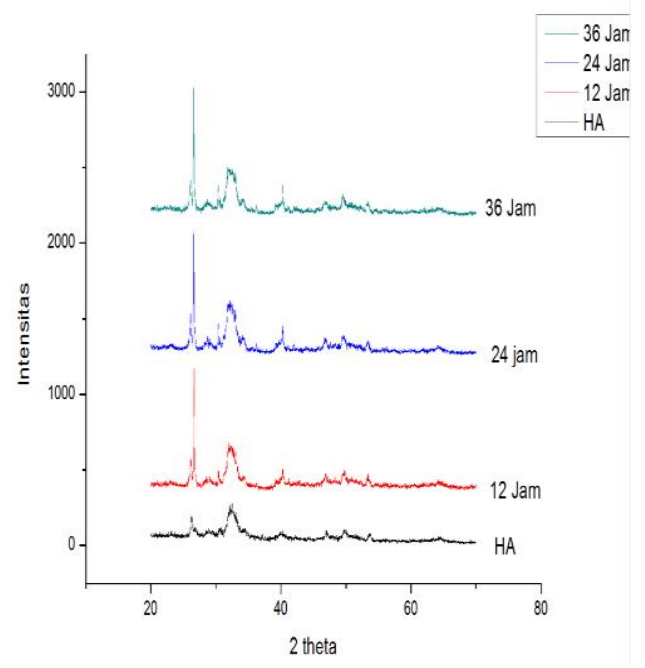

Dari hasil XRD dapat dihitung nilai ukuran butir dan derajat kristalinitas sama seperti pada saat menghitung nilai ukuran butir dan kristalinitas pada HA. Nilai ukuran butir komposit HA-PEG ditunjukkan pada tabel 1.

Tabel 1. Perhitungan Ukuran Butir Kristal Komposit Hidroksiapatit-PEG

\begin{tabular}{|l|l|l|l|l|l|}
\hline $\begin{array}{l}\text { Lama } \\
\text { Maturasi }\end{array}$ & $\mathrm{k}$ & $\begin{array}{l}\lambda \\
(\mathrm{nm})\end{array}$ & $\begin{array}{l}F W H M \\
(\mathrm{rad})\end{array}$ & $\begin{array}{l}\cos \theta_{\text {FWHM }} \\
(\mathrm{nm})\end{array}$ \\
\hline 12 Jam & 0,9 & 0,15406 & 0.0034480 & 0.9741933 & 41.27 \\
\hline 24 Jam & 0,9 & 0,15406 & 0.0030396 & 0.9741911 & 46.82 \\
\hline 36 Jam & 0,9 & 0,15406 & 0.005176 & 0.9742050 & 27.49 \\
\hline
\end{tabular}


Dari Tabel 1 dibuat grafik hubungan pengaruh lama maturasi terhadap ukuran butir kristal komposit hidroksiapatit-PEG seperti pada gambar 3.

Gambar 3 Grafik Hubungan Lama Maturasi Terhadap Ukuran Butir Kristal HA-PEG

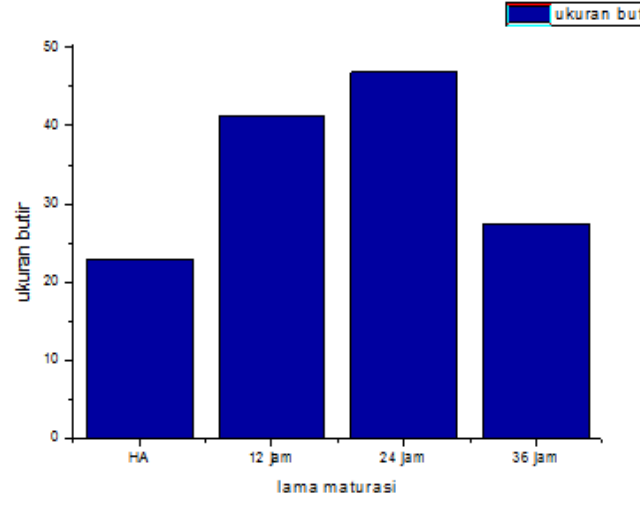

Gambar 3 menunjukkan grafik hubungan lama maturasi terhadap ukuran butir komposit hidroksiapatit-PEG. Ukuran butir kristal mengalami penurunan pada lama maturasi 36 jam. Sedangkan hasil perhitungan derajat kristalinitas komposit HA-PEG ditunjukkan pada tabel 2.

Tabel 2 Hasil Perhitungan Derajat Kristalinitas Komposit HA-PEG

\begin{tabular}{|l|l|l|l|}
\hline $\begin{array}{l}\text { Lama } \\
\text { Maturasi }\end{array}$ & $\begin{array}{l}\text { Luas } \\
\text { Total }\end{array}$ & $\begin{array}{l}\text { Luas } \\
\text { Amorf }\end{array}$ & $\begin{array}{l}\% \\
\text { Kristalinitas }\end{array}$ \\
\hline HA & 3522,97358 & 1818,38663 & $48,38 \%$ \\
\hline 12 Jam & 5667,08033 & 1818,38663 & $61,03 \%$ \\
\hline 24 Jam & 4682,80787 & 1818,38663 & $61,16 \%$ \\
\hline 36 Jam & 4583,88003 & 1818,38663 & $60,33 \%$ \\
\hline
\end{tabular}

Dari tabel 2 dapat dibuat grafik hubungan antara lama maturasi dengan derajat kristalinitas komposit hidroksiapatit-PEG seperti Gambar 4.

Gambar 4. Grafik Hubungan Lama Maturasi dan Derajat Kristalinitas Komposit HA-PEG

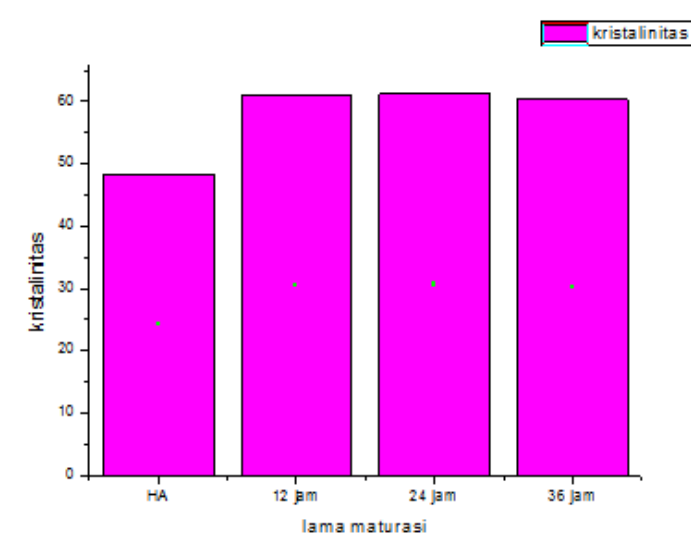


Gambar 4 menunjukkan bahwa semakin lama maturasi nilai derajat kristalinitas semakin tinggi, namun pada saat lama maturasi 36 jam terjadi penurunan derajat kristalinitas. Hal ini menunjukkan bahwa terdapat waktu yang optimum untuk memperbesar derajat kristalinitas. Setelah melewati waktu optimum, maka derajat kristalinitas tidak dapat menjadi lebih tinggi lagi tetapi justru kembali rendah.

\subsection{Data Hasil Uji SEM}

\section{Gambar 5. Hasil Uji SEM}
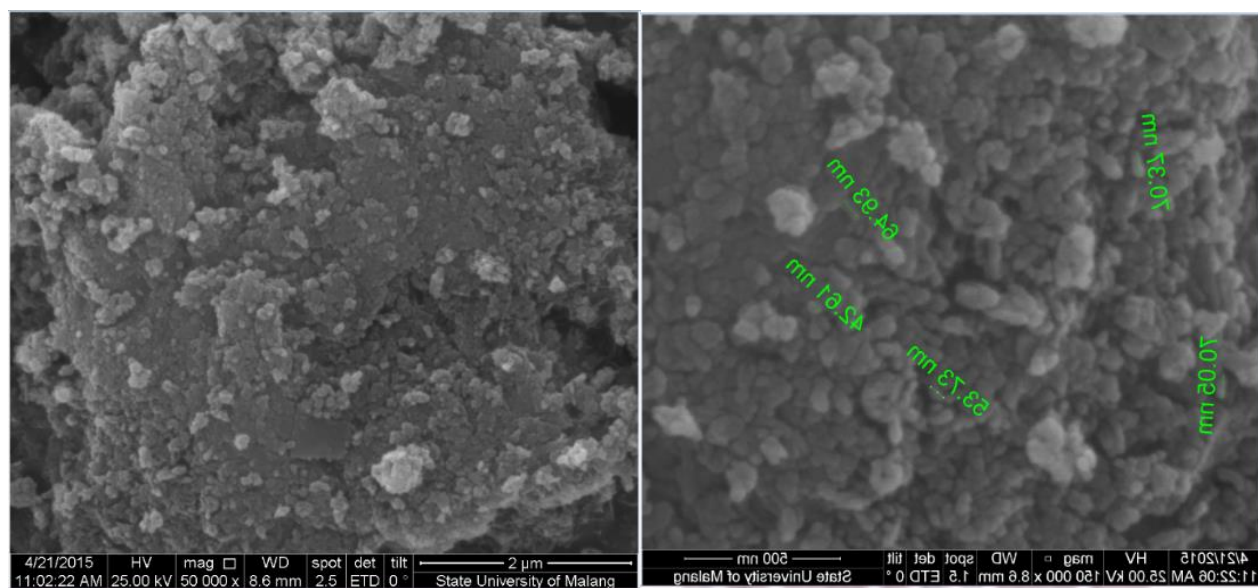

Hasil SEM HA seperti yang ditunjukkan pada Gambar 2. Dari hasil mikrostruktur ini diketahui bahwa partikel-partikel HA beraglomerasi. Aglomerasi partikel terjadi melewati beberapa tahapan, yaitu (a) nukleasi dan pertumbuhan partikel dalam orde nano, (b) agregasi partikel akibat interaksi secara fisis, dan (c) pertumbuhan kristal pada supersaturasi residual yang konstan.

\subsection{Data Hasil Uji Kekerasan}

\section{Gambar 6. Grafik Hubungan Lama Maturasi Terhadap Vicker Hardness}

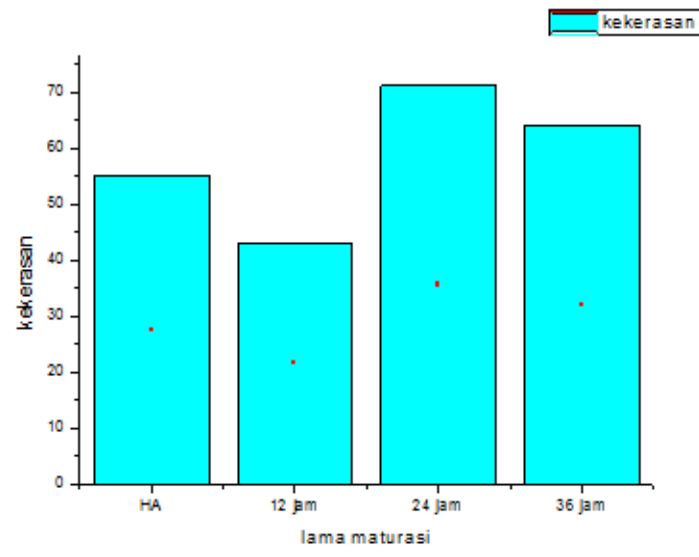

Gambar 6 Menunjukkan pengaruh lama maturasi terhadap kekerasan Vicker (Vicker Hardness). Dari gambar 6 terlihat bahwa nilai kekerasan Vicker (Vicker Hardness) bertambah besar dengan bertambah lamanya waktu maturasi yang diberikan, nilai kekersan Vicker (Vicker Hardness) yang paling besar adalah pada saat maturasi 24 jam. Namun, pada saat maturasi 36 jam 
nilai kekerasan menurun. Hal ini dikarenakan derajat kristalinitas pada saat lama maturasi 36 jam nilai derajat kristalinitas menurun.

\section{Simpulan}

4.2. Hidroksiapatit telah berhasil disintesis menggunakan bahan dasar calcite Puger dengan ditandai hampir semua puncak sampel sesuai dengan data model pada highscore plus. Hidroksiapatit yang dihasilkan dengan metode kopresipitasi berukuran nanometer, yang dihitung dengan menggunakan rumus Scharer didapat ukuran dari hidroksiapatit 22,87 $\mathrm{nm}$. Dengan menggunakan metode ini diperoleh perbandingan $\mathrm{Ca} / \mathrm{P}$ hasil sintesis sebesar 1,68 yang sama dengan perbandingan $\mathrm{Ca} / \mathrm{P}$ standar yaitu sebesar $1,67 \approx 2.00$.

4.3. Peningkatan lama maturasi memberikan pengaruh terhadap tingginya derajat kristalinitas. Semakin tinggi lama maturasi yang diberikan maka semakin tinggi juga derajat kristalinitas.Akan tetapi ketika lama maturasi dinaikkan menjadi 36 jam, derajat kristalinitas menurun. Hal ini menunjukkan bahwa terdapat waktu yang optimum untuk memperbesar derajat kristalinitas. Setelah melewati waktu optimum, maka derajat kristalinitas tidak dapat menjadi lebih tinggi lagi tetapi justru kembali rendah.

4.4. Lama maturasi juga memberikan pengaruh pada sifat mekanik. Hal ini berkaitan dengan kesimpulan pada poin 2 yang menyatakan bahwa semakin tinggi lama maturasi yang diberikan maka semakin besar juga derajat kristalinitas. Dengan semakin tingginya derajat kristalinitas komposit hidroksiapatit-PEG, maka semakin besar pula nilai kekerasan.

\section{Daftar Rujukan}

Abdullah, M., Khairurrijal, K., \& Khairurrijal, K. (2009). Karakterisasi nanomaterial. Jurnal Nanosains \& Nanoteknologi, 2(1), 1-9.

Bhattacharjee, P., Begam, H., \& Chanda, A. (2011). Development and physical, chemical and mechanical characterization of doped hydroxyapatite. International Journal of Scientific \& Engineering Research, 2(4), 1-8.

Crowley, J., \& Chalivendra, V. B. (2008). Mechanical characterization of ultra-high molecular weight polyethylene-hydroxyapatite nanocomposites. Bio-medical materials and engineering, 18(3), 149-160.

Darwis, D., \& Warastuti, Y. (2013). Sintesis dan karakterisasi komposit hidroksiapatit (HA) sebagai graft tulang sintetik. Jurnal Ilmiah Aplikasi Isotop dan Radiasi, 4(2).

Dasgupta, P., Singh, A., Adak, S., \& Purohit, K. M. (2004). Synthesis and characterization of hydroxyapatite produced from eggshell. In Proceedings of the International Symposium of Research Students on Materials Science and Engineering (pp. 1-6).

Delmifiana, B. (2013). Pengaruh sonikasi terhadap struktur dan morfologi nanopartikel magnetik yang disintesis dengan metode kopresipitasi. Jurnal Fisika Unand, 2(3).

Dhanalakshmi, C. P., Vijayalakshmi, L., \& Narayanan, V. (2012). Synthesis and characterization of FHAp/Chitosan nanocomposite and its biomedical application. Int. J. Nano \& Matl. Sci, 1(2), 81-96.

Eslami, H., Tahriri, M., \& Bakhshi, F. (2010). Synthesis and characterization of nanocrystalline hydroxyapatite obtained by the wet chemical technique. Materials Science-Poland, 28(1), 5-13.

Overgaard, S., Bromose, U., Lind, M., Bünger, C., \& Søballe, K. (1999). The influence of crystallinity of the hydroxyapatite coating on the fixation of implants: mechanical and histomorphometric results. The Journal of bone and joint surgery. British volume, 81(4), 725-731.

Park, J. (2009). Bioceramics: properties, characterizations, and applications (Vol. 741). Springer Science \& Business Media.

Rachmania, A. (2012). Preparasi Hidroksi apatit dari Tulang Sapi dengan Metode Kombinasi Ultrasonik dan Spray Drying (Doctoral dissertation, Tesis). 
Safronova, T. V., Shiryaev, M. A., Putlyaev, V. I., Murashov, V. A., \& Protsenko, P. V. (2009). Ceramics based on hydroxyapatite synthesized from calcium chloride and potassium hydrophosphate. Glass and Ceramics, 66(1), 66-69.

Yudyanto, H., \& Diantoro, M. (2013). Sintesis Nano-Hydroxyapatit Berbahan Dasar Batuan Alam Calcite Druju Kabupaten Malang sebagai Biomaterial Fungsional Pengganti Tulang. Jurnal Foton.

Zhang, X. (2007). Preparation and characterization of calcium phosphate ceramics and composites as bone substitutes. University of California, San Diego. 